\title{
Synthesis of Tachyhydrite and Bischofite for isotopic calibration measurements
}

GAUCHER, ERIC C. ${ }^{1}$; PICHAT, ALEXANDRE ${ }^{2}$; FERRAGE, ERIC ${ }^{3}$; Lerouge, CATHERINE ${ }^{4}$; FleHOC, Christine; AGRINIER, PIERRE 5 .

${ }^{1}$ TOTAL, CSTJF, avenue Larribau, 64000 Pau, France, (eric.gaucher@total.com)

${ }^{2}$ E2S-UPPA, IPRA, Univ. Pau \& Pays Adour; 64013, Pau, France (alexandre.pichat@gmail.com)

${ }^{3}$ IC2MP UMR 7285 - Université de Poitiers, Poitiers, France (eric.ferrage@univ-poitiers.fr)

${ }^{4}$ BRGM, Orléans, France (c.flehoc@brgm.fr)

${ }^{5}$ IPGP, Paris, France (agrinier@ipgp.fr)

Tachyhydrite $\left(\mathrm{CaMg}_{2} \mathrm{Cl}_{6}: 12 \mathrm{H}_{2} \mathrm{O}\right)$ and Bischofite $\left(\mathrm{MgCl}_{2}: 6 \mathrm{H}_{2} \mathrm{O}\right)$ are two highly soluble salts that are difficult to study considering their high power of deliquescence upon exposure to moist atmosphere. They may represent extreme evaporation stage of seawater or evolved brines but could also have a pure hydrothermal origin. To unravel their complex origin, an isotopic characterization $\left(\delta^{37} \mathrm{Cl}\right.$ and $\left.\delta^{18} \mathrm{O} / \delta \mathrm{D}\right)$ is highly desirable.

In order to better interpret the data obtained by isotopic analysis on natural samples, an artificial synthesis of the two minerals have been realized. Fractionation is studied during the evaporation of the mother-solution before and during the precipitation of the salts. The method of precipitation consists in the dissolution of one or two hydroxides $\mathrm{MgOH}_{2}$ and $\mathrm{CaOH}_{2}$ in a titrated solution of $\mathrm{HCl}(6 \mathrm{M})$. When the dissolution of the hydroxides neutralizes exactly the acid, the stoichiometry of the minerals is perfectly verified. The solutions are finally evaporated in a glove box under nitrogen atmosphere with a constant moisture less than $0.5 \%$. The precipitation of the salts have been obtained in a period of 2 weeks at $25^{\circ} \mathrm{C}$ without any heating of the brines. The mineralogical nature of the salts have been verified by XRD spectroscopy using a moisture control chamber. The brines and the salts have been analysed for $\delta^{18} \mathrm{O} / \delta \mathrm{D}$ after an adapted extraction of $\mathrm{H}_{2} \mathrm{O}$ molecules using lyophilisation techniques. 